Thomas Eich, Islam und Bioethik. Eine kritische. Analyse der modernen Diskussion im islamischen Recht \& Johannes Grundmann, Islamische Internationalisten. Strukturen und Akttivitäten der Muslimbruderschaft und der Islamischen Weltliga

Wiesbaden, Reichert Verlag, coll. « HECEAS/Aktuelle Debatte », 1, 2005, 127 p.\& Wiesbaden, Reichert Verlag, coll. « HECEAS/Aktuelle Debatte », $2,2005,118 \mathrm{p}$.

Hartmut Fähndrich

\title{
OpenEdition
}

Édition électronique

URL : http://journals.openedition.org/assr/6062

DOI : 10.4000/assr.6062

ISSN : $1777-5825$

Éditeur

Éditions de l'EHESS

Édition imprimée

Date de publication : 1 juin 2007

Pagination : 97-251

ISBN : 978-2-7132-2143-9

ISSN : 0335-5985

Référence électronique

Hartmut Fähndrich, «Thomas Eich, Islam und Bioethik. Eine kritische. Analyse der modernen Diskussion im islamischen Recht \& Johannes Grundmann, Islamische Internationalisten. Strukturen und Akttivitäten der Muslimbruderschaft und der Islamischen Weltliga ", Archives de sciences sociales des religions [En ligne], 138 | avril - juin 2007, document 138-36, mis en ligne le 11 septembre 2007, consulté le 21 septembre 2020. URL : http://journals.openedition.org/assr/6062 ; DOI : https://doi.org/10.4000/assr.6062

Ce document a été généré automatiquement le 21 septembre 2020.

(c) Archives de sciences sociales des religions 


\section{Thomas Eich, Islam und Bioethik. Eine kritische. Analyse der modernen Diskussion im islamischen Recht \& Johannes Grundmann, Islamische Internationalisten. Strukturen und Akttivitäten der Muslimbruderschaft und der Islamischen Weltliga}

Wiesbaden, Reichert Verlag, coll. « HECEAS/Aktuelle Debatte », 1, 2005, 127 p.\& Wiesbaden, Reichert Verlag, coll. « HECEAS/Aktuelle Debatte », $2,2005,118 \mathrm{p}$.

Hartmut Fähndrich

1 Voilà une nouvelle série dont les deux premiers volumes, bien que peu volumineux, sont pourtant tout à fait prometteurs et importants. La série semble être conçue sur le modèle du "Que sais-je? » avec une restriction thématique qui découle du fait que l'institution responsable de la publication de la série est le « Heidelberger Centrum für Euro-Asiatische Studien » qui, apparemment, vise dans chaque livre à une présentation profonde d'un thème d'intérêt général. Les deux premiers volumes en sont de bons exemples.

2 Le premier volume traite de la bioéthique, cette "étude des problèmes moraux soulevés par la recherche biologique, médicale ou génétique, et par certaines de ses applications » (Petit Larousse illustré), et cela dans le cadre de la perspective ou plutôt des perspectives musulmanes. Le second volume présente des/les internationalistes musulmans ou, ainsi que l'annonce le sous-titre, les structures et les activités de l'organisation des frères musulmans et de la Ligue musulmane mondiale. 
3 L'étude de l'islam et de la bioéthique se base sur les publications et la documentation de trois organisations et de quelques particuliers. Ces organisations sont l'Islamic Organization of Medical Sciences (IOMS), l'Islamic Fiqh Academy (IFA) affiliée à l'Organization of Islamic Conference à Jeddah, et l'Islamic Fiqh Academy affiliée, elle, à la Ligue musulmane mondiale à la Mecque. Ces trois organisations, composées majoritairement de juristes (fuqahâ') spécialistes de la charia, se réunissent régulièrement pour débattre de questions posées par le développement des sciences biologiques, et publient les textes des communications. Le but du livre de Thomas Eich n'est en fait que «l'analyse critique des discussions dans le cadre de la loi islamique » (p.17), et l'auteur arrive à la conclusion que « jusqu'ici il n'existe pas, parmi les savants de la loi, un consensus sur des questions centrales concernant l'appréciation éthique et légale de la technologie génétique ».

4 Les débats tournent, bien sûr, autour de quelques questions centrales telles que: l'embryogénèse, le début de la vie et la nécessité de protéger cette vie, la recherche sur les embryons et la technologie génétique (diagnostic préimplantatoire, diagnostic prénatal, clonage), débats dans lesquels ne s'engagent pas seulement les musulmans croyants mais aussi les chrétiens et les juifs. Car ces débats touchent au fondement de l'image de l'être humain à travers des écritures dites sacrées ou des traditions dérivées.

5 Dans les résultats de la présentation de Th. Eich, il y a trois ou quatre points d'envergure majeure :

6 Le problème, ou peut-être même l'impossibilité, d'harmoniser des traditions dogmatiques (glanées et développées dans les textes sacrées, Coran et Hadîth) avec les données scientifiques modernes si l'on n'est pas prêt à abandonner la compréhension littérale des textes transmis pour une interprétation symbolique. Cela se pose pour la question sur le début de la vie ou, formulé « islamiquement », sur l'entrée de l'âme dans l'embryon. Est-ce le quarantième jour, comme disent les uns, ou plutôt le centvingtième jour, comme affirment les autres, tous se basant sur des textes de la grande période de l'islam? Et comment interpréter les passages coraniques traitant du développement prénatal. De plus, est-il permis de considérer l'embryon, avant qu'il ne reçoive l'âme, comme une plante et avec quelles conséquences pour fixer le terme de la vie à protéger, toutes questions importantes pour les discussions sur la contraception, l'avortement et la recherche sur embryons. Les débats présentés par Thomas Eich démontrent clairement que, dans ce domaine, il n'y a pas de consensus parmi les savants, médecins ou théologiens.

7 Le second volume de la série, traitant des organisations islamistes internationalistes, met l'accent sur les réseaux plutôt que sur les doctrines. Il présente l'organisation des Frères musulmans et la Ligue musulmane mondiale.

8 L'organisation des Frères musulmans, originaire d'Égypte, est active aujourd'hui dans plus de soixante-dix pays. Elle agit pour changer le système de l'intérieur et transformer les sociétés des musulmans en sociétés musulmanes avec, pour but final, l'unification de ces sociétés plurielles en une société unique.

9 Ce qui est particulièrement intéressant dans l'étape actuelle, c'est l'organisation nationale des Frères musulmans et les arrangements du groupe ou des groupes dans chaque pays avec les régimes au pouvoir. À ce sujet, l'auteur consacre quelques lignes au rôle joué par les Frères musulmans, non seulement dans de nombreux pays musulmans arabes ou asiatiques, mais dans plusieurs pays européens. En conclusion du 
chapitre, on trouve deux pages sur Tariq Ramadan, dont l'auteur juge le rôle ambigu (kontextabhängig).

10 La Ligue, fondée en 1962 à la Mecque, se présente comme une ONG bien qu'il s'agisse, en fait, d'un outil de la politique extérieure de l'Arabie saoudite pour la diffusion internationale de l'islam selon les Wahhabites. Créée pour combattre le nationalisme arabe, la Ligue alimente, aujourd'hui, globalement des centaines de mosquées, de centres culturels et les salaires des imams.

11 À propos des différends croissants entre l'organisation des Frères musulmans et la monarchie wahhabite, il sera intéressant d'observer le développement des deux organisations internationalistes et les rapports entre elles qui, toutes deux, veulent "travailler à une islamisation sournoise des pays et des sociétés non musulmanes, élargir la crevasse entre musulmans et non musulmans et imposer à la majorité des musulmans leur compréhension de l'islam » (p. 112). 